\title{
Analisis Perbandingan Respon Transfer Function Stirrer Tank Heater dengan Variasi Fluida Menggunakan MATLAB Simulink
}

\author{
Mochamad Denny Surindra \\ Teknik Mesin, Politeknik Negeri Semarang, \\ J1. Prof. H. Sudarto, S.H., Tembalang, Semarang, 50275 \\ E-mail: dennysurindra@polines.ac.id
}

Diterima: 21-02-2021; Direvisi: 31-03-2021; Dipublikasi: 27-04-2021

\begin{abstract}
Abstrak
Pemodelan stirrer tank heater yang memanaskan fluida air, methanol dan engine oil dianalisis dengan menurunkan transfer function system dan membuat coding dengan Matlab Simulink. Fluida air membutuhkan energy panas yang paling rendah dengan settling time 2,5175, methanol 5,624 dan engine oil 7,543. Kecepatan mencapai settling time methanol 16.910.661 detik, diikuti fluida air 20.658,043 detik dan engine oil 35.017.592 detik. Modifikasi system dengan menghilangkan gangguan, kebutuhan energy panas untuk air 1,5675, methanol 4,674 dan engine oil 6,593, lebih rendah jika dibandingkan dengan system yang masih melibatkan gangguan. Kecepatan settling time, methanol 16.933.221 detik diikuti dengan air 20.688.789 detik dan engine oil 34.196.792 detik.
\end{abstract}

Kata kunci: Matlab; Simulink; Heater; Tank; Fluida

\begin{abstract}
The modeling of the stirrer tank heater that heating water, methanol and engine oil is analyzed by reducing the transfer function system and coding with Matlab Simulink. Water fluid requires the lowest heat energy with a settling time of 2.5175, methanol 5.624 and engine oil 7.543. The speed achieved methanol settling time of 16,910,661 seconds, followed by water fluid 20,658.043 seconds and engine oil 35,017,592 seconds. Modification of the system by eliminating disturbances, the need for heat energy for water is 1.5675, methanol 4.674 and engine oil is 6,593, lower than the system that still involves disturbances. Speed settling time was shown methanol 16,933,221 seconds followed by water 20,688,789 seconds and engine oil 34,196,792 seconds.
\end{abstract}

Keywords: Matlab; Simulink; Heater; Tank; Fluida

\section{Pendahuluan}

Peningkatan teknologi kontrol telah banyak berkembang dari tahun ketahun dan diaplikasikan dalam berbagai bidang seperti motor DC [1,2], dan simulasi level air [3]. Aplikasi ilmu kontrol yang lebih komplek biasanya diterapkan di industri pembangkit [4,5] maupun skala laboratorium seperti yang dilakukan oleh Surindra et al [6,7]. Aplikasi dibidang perpindahan panas di heat exchanger sudah banyak dilakukan oleh Surindra [8-12] dalam penelitiannya di bidang ORC. Meskipun begitu pemodelan untuk memahami perpindahan panas dari sudut pandang control engineering masih sangat diperlukan untuk memberikan pemahaman didalam pembelajaran di bidang sistem pengaturan. Dengan demikian paper ini membahas pemodelan stirrer tank heater yang memanaskan fluida dengan menurunkan transfer function system dan membuat coding dengan Matlab Simulink. Fluida air sudah diteliti oleh Surindra [13].

\section{Material dan metodologi}

Sistem thermal menggunakan model Stirred Tank Heater seperti yang telah dibangun oleh Ogata [14] dimana dalam bukunya menggambarkan sebuat tangki yang rigid sehingga kondisinya adiabatik dan tidak ada energi kalor yang masuk ataupun keluar, selain itu tangki juga dilengkapi dengan pengaduk (stirrer) sehingga didapatkan temperature fluida yang sama atau seragam. Dalam tangki tersebut terpasang heater yang memanaskan fluida secara terus menerus sampai mencapai temperature yang diinginkan. Sedangkan ukuran tangki yang digunakan adalah $1 \mathrm{~m}^{3}$ adapun heater 
mempunyai tahanan thermal sesuai dengan masing-masing thermal conductivity fluida dalam fase cair dan pada temperature yang dipilih. Pemodelan Stirred Tank Heater dapat ditunjukan dalam Gambar 1.

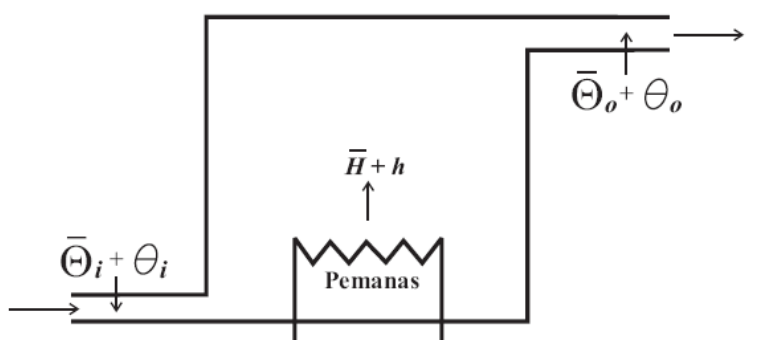

Gambar 1. Model Stirred Tank Heater

Fluida yang pertama digunakan adalah air dengan kondisi properties berdasarkan report penelitian dari Perusahaan Hot Disk $\mathrm{AB}$ yang mengukur air dengan menyuling untuk membuang semua ion. Fluda air dipilih pada suhu $20^{\circ} \mathrm{C}$ dan hasilnya kemudian menunjukkan $\mathrm{Cp}$ sebesar $4,186 \mathrm{~kJ} / \mathrm{m}^{3} \mathrm{~K}$. Satu kalori per definisi adalah jumlah energi yang dibutuhkan untuk menaikkan suhu satu gram air dengan satu derajat Celcius pada $20{ }^{\circ} \mathrm{C}$. Dalam satuan SI, pada suhu 20 ${ }^{\circ} \mathrm{C}$ massa jenis air murni adalah $1 \mathrm{~g} / \mathrm{cm}^{3}$ sehingga kalor jenis per satuan volume akan menjadi $4,18 \mathrm{MJ} / \mathrm{m}^{3}[15]$.

Tabel 1. Properties fluida yang digunakan dalam analisa (Air, Methanol, dan Engine Oil).

\begin{tabular}{ccc}
\hline Fluida & $\lambda[\mathrm{W} / \mathrm{m} / \mathrm{K}]$ & $\rho \mathrm{C}_{\mathrm{p}}\left[\mathrm{MJ} / \mathrm{m}^{3} \mathrm{~K}\right]$ \\
\hline Air & 0,6075 & 4,18 \\
Methanol & 0,203 & 1,149 \\
Engine Oil & 0,144 & 1,688 \\
\hline
\end{tabular}

Fluida methanol menjadi fluida kedua yang dipilih pada temperature $30{ }^{\circ} \mathrm{C}$ dengan konduktifitas thermal sebesar $0.203 \mathrm{~W} / \mathrm{m} / \mathrm{K}$. Pada temperature tersebut spesifik heat methanol sebesar $1,47 \mathrm{~kJ} / \mathrm{kg}$, sedangkan densitinya sebesar 782 $\mathrm{kg} / \mathrm{m}^{3}$. Dengan demikian pada sisi input temperature $\Theta_{\mathrm{i}}=30{ }^{\circ} \mathrm{C}$ dan terjadi penambahan temberatur $\theta_{\mathrm{i}}$ [16]. Fluida engine oil dipilih sebagai fluida ketiga pada temperature $300 \mathrm{~K}$ dengan properties density sebesar $884 \mathrm{~kg} / \mathrm{m}^{3} \mathrm{dan}$ spesifik heat sebesar $1,91 \mathrm{~kJ} / \mathrm{kg} . \mathrm{K}$, sedangkan untuk thermal conductivity sebesar $0,144 \mathrm{~W} / \mathrm{m} . \mathrm{K}$ [17]. Fluida ini merupakan minyak pelumas mesin yang memiliki berbagai macam spesifikasi sesuai dengan penggunakannya. Dari properties yang didapat ditabelkan dalam Tabel 1 untuk keperluan pembuatan coding Matlab.

\section{Hasil dan pembahasan}

Surindra [13] telah membangun model simulator tangki yang diisolasi sempurna sehingga tidak ada energy kalor yang masuk ataupun hilang ke udara luar. Selain itu diasumsikan tidak ada energy kalor yang tersimpan di dalam tangki tersebut serta pemanasan dilakukan secara sempurna oleh heater secara elektronik menggunakan heater, sehingga temperatur fluida merata diseluruh bagian tangki.

\subsection{Transfer Function Stirred Tank Heater}

Dengan meninjau deviasi kecil dari operasi keadaan steady, dimana rugi atau kehilangan kalor ke sekeliling dan kapasitansi kalor bagian metal dari pemanas dapat diabaikan. Masukan kalor berfluktuasi dari $\mathrm{H}$ menjadi $\mathrm{H}+\mathrm{h}$ dan 
temperature fluida masuk berubah dari $\Theta_{\mathrm{i}}$ menjadi $\Theta_{\mathrm{i}}+\theta_{\mathrm{i}}$. Akibatnya temperature udara keluar akan berubah dari dari $\Theta_{\mathrm{o}}$ menjadi $\Theta_{\mathrm{o}}+\theta_{\mathrm{o}}$. Persamaan yang megambarkan perilaku system tersebut adalah

$$
\begin{aligned}
& \mathrm{Cd} \theta_{\mathrm{o}}=\left[\mathrm{h}+\mathrm{Gc}\left(\theta_{\mathrm{i}}-\theta_{\mathrm{o}}\right)\right] \mathrm{dt} \text { atau } \\
& \mathbf{C} \frac{\mathbf{d} \boldsymbol{\theta}_{\mathbf{o}}}{\mathbf{d t}}=\mathbf{h}+\mathbf{G c}\left(\boldsymbol{\theta}_{\mathbf{i}}-\boldsymbol{\theta}_{\mathbf{o}}\right)
\end{aligned}
$$

Dengan memperhatikan bahwa

$$
\mathbf{G} \mathbf{c}=\frac{\mathbf{1}}{\mathbf{R}}
$$

diperoleh

$$
C \frac{d \theta_{0}}{d t}=h+\frac{1}{R}\left(\left(\theta_{i}-\theta_{0}\right)\right)
$$

atau

$$
R C \frac{d \theta_{0}}{d t}+\theta_{0}=R h+\theta_{i}
$$

Dengan mencari transformasi Laplace kedua ruas persamaan terakhir ini dan dengan substitusi syarat awal bahwa $\theta_{0}$ $(0)=0$, kita peroleh

$$
\Theta_{\mathbf{o}}(\mathbf{s})=\frac{\mathbf{R}}{\mathrm{RCs}+\mathbf{1}} \mathbf{H}(\mathbf{s})+\frac{1}{\mathrm{RCs}+\mathbf{1}} \boldsymbol{\Theta}_{\mathbf{i}}(\mathbf{s})
$$

Diagram block untuk kasus ini dapat didiskripsikan dalam gambar 2 seperti berikut ini

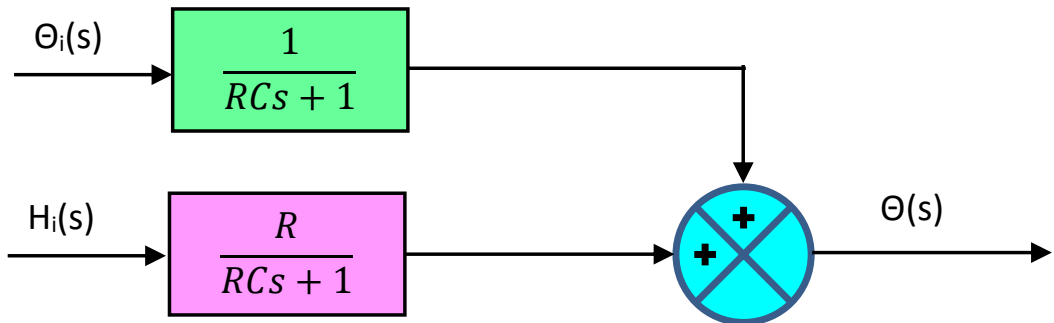

Gambar 2. Diagram Block Sistem thermal Stirred Tank Heater

Dengan demikian transfer function untuk perubahan laju kalor input dengan temperature output adalah $\frac{\boldsymbol{R}}{\boldsymbol{R C s}+\mathbf{1}}$, sedangkan untuk temperature cairan aliran masuk berfluktuasi adalah $\frac{1}{\boldsymbol{R C s}+\mathbf{1}}$ dan berfunsi sebagai gangguan (disturbance)

\subsection{Pemodelan Simulink Matlab}

Dari gambar diagram block system thermal stirred tank heater dapat dibuat pemodelan didalam Simulink sebagai berikut di Gambar 3.

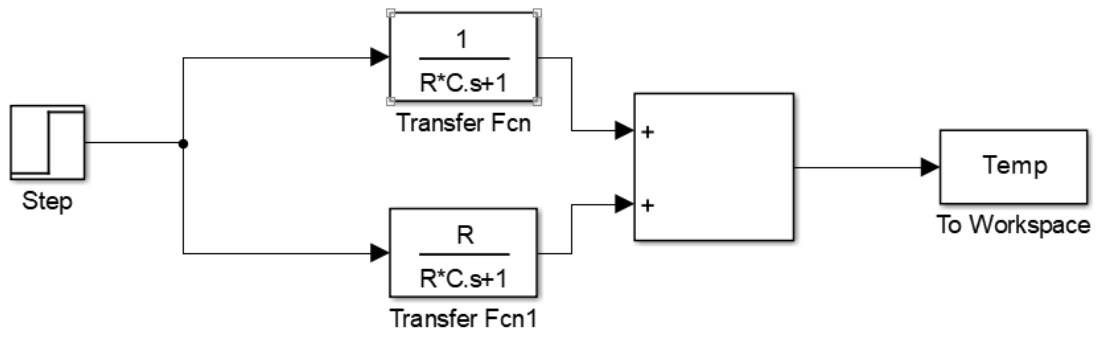

Gambar 3. Model simulasi Stirred Tank Heater menggunakan simulink 
Mochamad Deny S. /Jurnal Rekayasa Mesin

p-ISSN: 1411-6863, e-ISSN: 2540-7678

Vol.16|No.1|25-31|April|2021

Simulasi menggunakan fluida air dengan konduktifitas thermal sebesar $0.6075 \mathrm{~W} / \mathrm{m} / \mathrm{K}$ dan rho dikalikan dengan specific heatnya didapatkan 4,18 MJ/m ${ }^{3} \mathrm{~K}$. Untuk methanol dengan konduktifitas thermal sebesar $0,203 \mathrm{~W} / \mathrm{m} / \mathrm{K}$ dan rho dikalikan dengan specific heatnya $1,149 \mathrm{MJ} / \mathrm{m}^{3} \mathrm{~K}$, sedangkan engine oil memiliki konduktifitas thermal sebesar 0,144 $\mathrm{W} / \mathrm{m} / \mathrm{K}$ dan rho dikalikan dengan specific heatnya adalah sebesar $1,688 \mathrm{MJ} / \mathrm{m}^{3} \mathrm{~K}$, seperti yang ada didalam Tabel 1. Jika volume tangki yang digunakan adalah $1 \mathrm{~m}^{3}$, maka simulasi respon transfer function untuk ketiga fluida tersebut ditampilkan dalam Gambar 4. Selain itu fluida yang dipergunakan divariasikan dengan menggunakan methanol dan engine oil. Methanol mempunyai konduktifitas thermal sebesar $0,203 \mathrm{~W} / \mathrm{m} / \mathrm{K}$ dan rho dikalikan dengan specific heatnya didapatkan $1,149 \mathrm{MJ} / \mathrm{m}^{3} \mathrm{~K}$. Adapun engine oil memiliki konduktifitas thermal sebesar $0,144 \mathrm{~W} / \mathrm{m} / \mathrm{K}$ dan rho dikalikan dengan specific heatnya didapatkan $1,688 \mathrm{MJ} / \mathrm{m}^{3} \mathrm{~K}$. Data hasil run simulasi dengan menggunakan Matlab Simulink dapat ditabelkan seperti dalam Tabel 2.

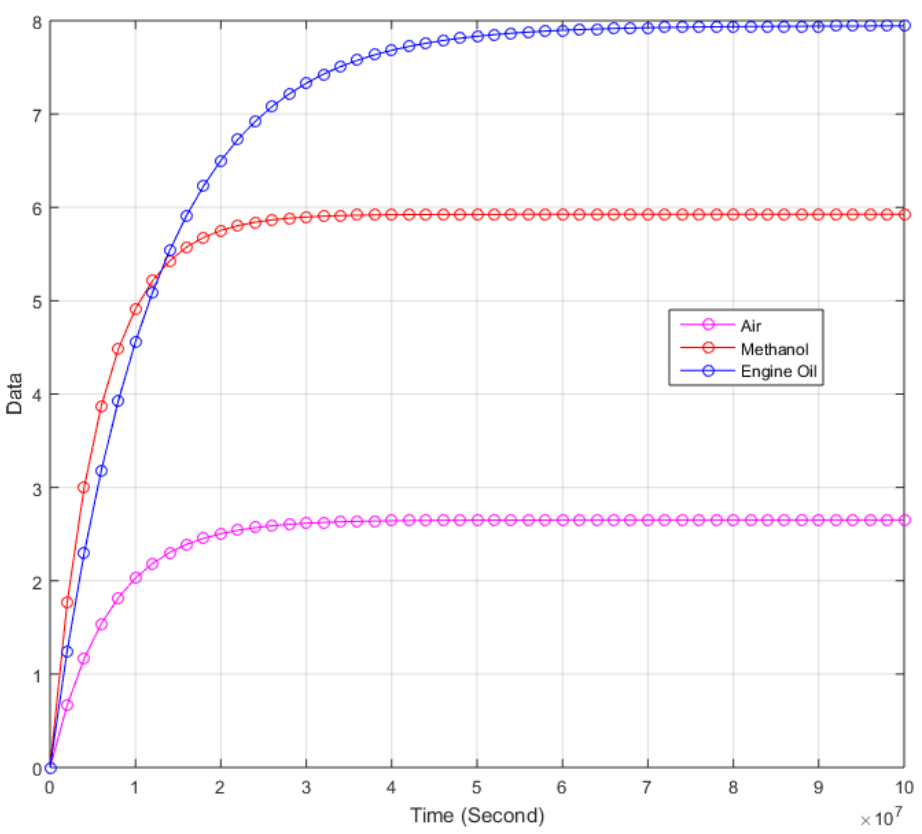

Gambar 4. Hasil run simulasi Stirred Tank Heater dengan Matlab Simulink

Tabel 2. Spesifikasi respon transient untuk Air, Methanol dan Engine Oil

\begin{tabular}{lcccccc}
\hline \multirow{2}{*}{ Discription } & \multicolumn{2}{c}{ Air } & \multicolumn{2}{c}{ Methanol } & \multicolumn{2}{c}{ Engine Oil } \\
\cline { 2 - 7 } & Data & Time $(\mathrm{s})$ & Data & Time $(\mathrm{s})$ & Data & Time $(\mathrm{s})$ \\
\hline Rise time start, tr1 & 0,265 & 794.462 & 0,592 & 671.055 & 0,794 & 1.274 .249 \\
Delay time, td & 1,325 & 4.848 .927 & 2,96 & 3.929 .682 & 3,97 & 8.127 .414 \\
Rise time end, tr2 & 2,385 & 15.744 .783 & 5,328 & 12.000 .001 & 7,146 & 28.966 .564 \\
Settling time, ts & 2,5175 & 20.658 .043 & 5,624 & 16.910 .661 & 7,543 & 35.017 .592 \\
\hline
\end{tabular}

Dari grafik dan table dapat dilihat bahwa fluida air memiliki data yang paling rendah jika dibandingkan dengan fluida yang lain dimana data settling time 2,5175 sedangkan methanol mencapai 5,624 dan engine oil tercatat tertinggi dibanding keduanya sebesar 7,543. Hal ini dapat dikatakan bahwa engine oil membutuhkan energy yang paling besar untuk mencapai posisi settling time. Untuk kecepatan mencapai settling time, methanol mencatat waktu yang paling cepat jika dibandingkan fluida yang lain yaitu 16.910.661 detik, sedangkan air tercatat lebih lama untuk mencapai posisi settling time sebesar 20.658,043 detik dan terakhir engine oil sebesar 35.017.592 detik. 
Mochamad Deny S. /Jurnal Rekayasa Mesin

p-ISSN: 1411-6863, e-ISSN: 2540-7678

Vol.16|No.1|25-31|April|2021

\subsection{Pemodelan Simulink Matlab dengan menghilangkan Gangguan}

Sisi input air dingin masuk merupakan gangguan terhadap system stirrer tank heater sehingga dapat diasumsikan ketika pengisian air dan tangki sudah penuh, maka katub ditutup sehingga tidak ada air masuk lagi, maka kotak block yang mewakili air dingin masuk dapat dihilangkan. Gambar 5 mensimulasikan kondisi tersebut.

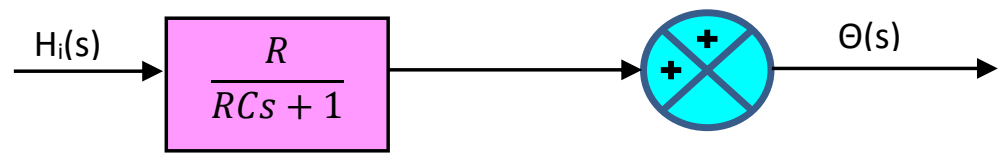

Gambar 5. Diagram Block Sistem thermal Stirred Tank Heater tanpa gangguan

Kalau digambarkan dalam Matlab dapat ditunjukan seperti didalam Gambar 6. Hasil run simulasi dengan Matlab Simulink dihasilkan gambar Grafik 7 dimana hasilnya identik dengan yang melibatkan gangguan hanya saja ketika gangguan dihilangkan posisi settling time lebih rendah. Data dari Gambar 7 dicatat dalam Tabel 3 yang mana terbaca bahwa semua fluida menghasilkan posisi settling time yang lebih rendah dari sebelumnya.

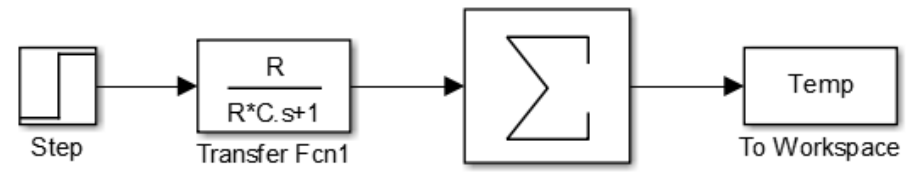

Gambar 6. Model simulasi Stirred Tank Heater tanpa gangguan menggunakan simulink

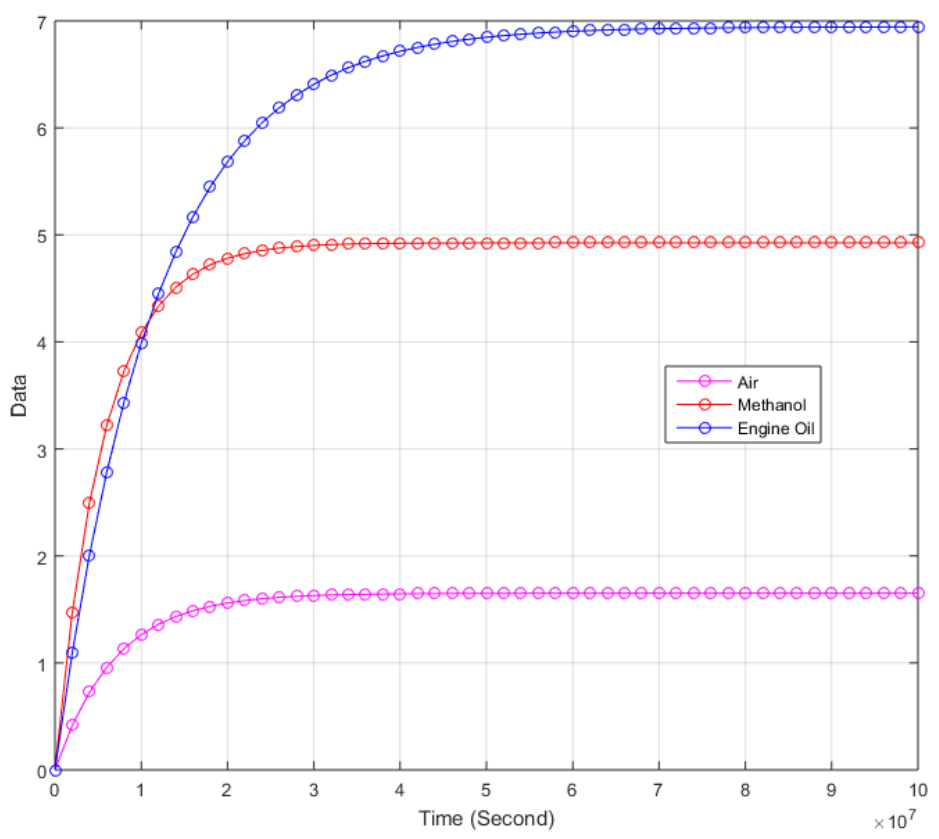

Gambar 7. Hasil run simulasi Stirred Tank Heater dengan Matlab Simulink

Tabel 3. Spesifikasi respon transient untuk Air, Methanol dan Engine Oil tanpa gangguan

\begin{tabular}{ccccccc}
\hline \multirow{2}{*}{ Discription } & \multicolumn{2}{c}{ Air } & \multicolumn{2}{c}{ Methanol } & \multicolumn{2}{c}{ Engine Oil } \\
\cline { 2 - 7 } & Data & Time $(\mathrm{s})$ & Data & Time $(\mathrm{s})$ & Data & Time $(\mathrm{s})$ \\
\hline Rise time start, tr1 & 0,165 & 794.640 & 0,492 & 671.196 & 0,694 & 824.417 \\
Delay time, td & 0,825 & 4.850 .519 & 2,46 & 3.930 .683 & 3,47 & 8.128 .431 \\
Rise time end, tr2 & 1,485 & 15.884 .602 & 4,428 & 13.068 .805 & 6,246 & 26.975 .059 \\
Settling time, ts & 1,5675 & 20.688 .789 & 4,674 & 16.933 .221 & 6,593 & 34.196 .792 \\
\hline
\end{tabular}


Data air settling time tercatat 1,5675 diikuti methanol dengan 4,674 dan engine oil 6,593, sedangkan untuk kecepatan settling time, methanol tercatat 16.933.221 detik diikuti dengan air sebesar 20.688 .789 detik dan engine oil sebesar 34.196.792 detik.

\section{Kesimpulan}

Analisis simulasi stirrer tank dengan menggunakan Matlab Simulink dapat diambil kesimpulan. Fluida air menunjukan kebutuhan energy panas yang paling rendah dengan settling time 2,5175 sedangkan methanol mencapai 5,624 dan engine oil tercatat tertinggi dibanding keduanya sebesar 7,543. Adapun untuk kecepatn mencapai settling time methanol mencatat waktu 16.910.661 detik, diikuti fluida air 20.658,043 detik dan engine oil 35.017.592 detik. Ketika gangguan system dihilangkan, kebutuhan energy panas untuk air settling time tercatat 1,5675 methanol 4,674 dan engine oil 6,593, lebih rendah jika dibandingkan dengan system yang masih melibatkan gangguan, sedangkan untuk kecepatan settling time, methanol 16.933.221 detik diikuti dengan air 20.688.789 detik dan engine oil 34.196.792 detik.

\section{Nomenklatur}

$\Theta_{\mathrm{i}}: \quad$ Temperature steady fluida masuk, ${ }^{\circ} \mathrm{C}$

$\mathrm{H}_{\mathrm{i}}$ : $\quad$ laju kalor input steady, $\mathrm{W}$

$\Theta_{\mathrm{o}}: \quad$ Temperature steady fluida keluar, ${ }^{\circ} \mathrm{C}$

$\mathrm{G}$ : $\quad$ laju aliran fluida steadi, $\mathrm{kg} / \mathrm{det}$

$\mathrm{h}_{\mathrm{i}}: \quad$ perubahan kecil dari laju kalor input, $\mathrm{W}$

$\mathrm{M}$ : $\quad$ massa fluida dalam tangki, $\mathrm{kg}$

c : $\quad$ kalor jenis fluida, $\mathrm{J} / \mathrm{N}^{\circ} \mathrm{C}$

$\mathrm{R}$ : $\quad$ resistansi termal, ${ }^{\circ} \mathrm{C} / \mathrm{W}$

$\mathrm{C}: \quad$ kapasitansi termal, $\mathrm{J} / \mathrm{N}^{\circ} \mathrm{C}$

$\mathrm{H}$ : $\quad$ laju kalor input steady, $\mathrm{W}$

$h_{0}$ : $\quad$ perubahan kecil dari laju kalor output, $W$

$\theta$ : $\quad$ perubahan temperature cairan output, ${ }^{\circ} \mathrm{C}$

$\theta_{\mathrm{i}}$ : $\quad$ perubahan temperature cairan input, ${ }^{\circ} \mathrm{C}$

$\lambda: \quad$ konduktivitas thermal, $\mathrm{W} / \mathrm{m} / \mathrm{K}$

$\mathrm{Cp}: \quad$ specific heat, $\mathrm{J} /(\mathrm{K} \mathrm{kg})$

\section{Daftar Pustaka}

[1] Surindra, M.D., Widyaningsih, W.P., Margana, Supriyo, Mulud, T.H., Sistem Kontrol Proportional Integral Derivative (PID) Untuk Mengatur Kecepatan Motor DC Menggunakan Mikrokontroller, Prosiding Seminar Nasional (NCIET); 7 November 2020; Semarang, Indonesia. 2020. Vol.1: p. B528-B534.

[2] Surindra M.D., Analisis Respon Output Dari Pemodelan Kontrol Proporsional Pada Aktuator Motor DC. Eksergi Jurnal Teknik Energi. 2013 Mei, Vol. 9 No. 2: p. 43-46.

[3] Surindra, M.D., Design Simulator Fresh Water Tank di PLTU Dengan Water Level Control Menggunakan Mikrokontroler. Prosiding SNST ke-3 Tahun 2012 Fakultas Teknik Universitas Wahid Hasyim Semarang: p. B79-84.

[4] Surindra, M.D., Analisis Variasi Nilai Kalor Batubara Di PLTU TANJUNG JATI B Terhadapa Energi Input System. Jurnal Rekayasa Mesin. 2014 Desember, Vol.9, No.3: p. 93-100.

[5] Jev N. Hilga, Sunarwo, Surindra, M.D., Pengaruh Perubahan Beban Terhadap Sistem Uap Ekstraksi Pada Dearator PLTU TANJUNG JATI B UNIT 2. Eksergi Jurnal Teknik Energi, 2014 September, Vol 10, No. 3: p. 9498.

[6] Surindra, M.D., Eksperimental Studi Aplikasi Panel Surya Monocrystalline 50 WP Sebagai Sumber Tenaga Aerator Dengan Aliran Kombinasi Horizontal dan Vertikal. Eksergi Jurnal Teknik Energi. 2020 September, Vol.16 No. 3: p. 99-108.

[7] Surindra, M.D., Analisis Karakteristik Elextrical Modul Photovoltaic Untuk Pembangkit Listrik Tenaga Surya Skala Laboratorium. Prosiding SNST ke- Tahun 2012. Fakultas Teknik Universitas Wahid Hasyim Semarang, p. B74-B78. 
Mochamad Deny S. /Jurnal Rekayasa Mesin

p-ISSN: 1411-6863, e-ISSN: 2540-7678

Vol.16|No.1|25-31|April|2021

[8] Surindra, MD.; Eksperimental Studi Performance Organic Rankine Cycle (ORC) Mneggunakan Fluida Kerja R245fa dengan Sumber Panas di Evaporator 120ㄷ. Jurnal Rekayasa Mesin. 2019 Desember, Vol.14, No.3: p. 135-141.

[9] Surindra, M.D.; Caesarendra, W.; Prasetyo, T.; Mahlia, T.M.I.; Taufik, T. Comparison of the Utilization of $110{ }^{\circ} \mathrm{C}$ and $120{ }^{\circ} \mathrm{C}$ Heat Sources in a Geothermal Energy System Using Organic Rankine Cycle (ORC) with R245fa, R123, and Mixed-Ratio Fluids as Working Fluids. Processes. 2019; (7): p. 113.

[10] Prasetyo, T.; Surindra, M.D., Caesarendra, W., Taufik, T. Glowacz A., Irfan M., Glowacz. W., Influence of Superheated Vapour in Organic Rankine Cycles with Working Fluid R123 Utilizing Low-Temperature Geothermal Resources. Symmetry. 2020; 12(9): p. 1463.

[11] Surindra, M.D., Performance Organic Rankine Cycle System (ORCS) Dengan Fluida Kerja HCFC123 Menggunakan Temperature Gas Buang Yang Rendah. Prosiding Seminar Nasional NCIET $1^{\text {st }}$ National Conference of Industry, Engineering and Technology 2020, Semarang, Indonesia. Vol.1 (2020): p. B293-B300.

[12] Surindra, M.D., Caesarendra, W. Investigation Study of Pressure Different Effect at Evaporator in Organic Rankine Cycle Simulator (ORCS) Using Low-grade Waste Heat. Proceedings of the 4th Forum in Research, Science, and Technology (FIRST-T1-T2-2020): p. 456-464.

[13] Surindra, M.D., Studi Analisis Sistem Fisik Thermal Dengan Pemodelan Stirrer Tank Heater Menggunakan SIMULINK MATLAB. Eksergi Jurnal Teknik Energi. 2021 Januari, Vol.17 No.1: p. 57-66.

[14] Ogata, K. Laksono E., Teknik Kontrol Automatik (Sistem Pengaturan), etakan ke empat. Penerbit Erlangga; 1991. p. 115.

[15] Häldahl, L. Measurement Accuracy and Thermal Conductivity of Water. https://www.hotdiskinstruments.com/ applications/measurement-accuracy-and-thermal-conductivity-of-water/, Hot Disk. Chalmers University of Technology, Sweden. (Diakses pada tanggal 14 Feb 2021).

[16] Methanol - Thermophysical Properties at varying temperature. https://www.engineeringtoolbox.com/methanolproperties-d_1209.html. The Engineering Tool Box. Thermophysical properties of methanol; 2008 (Diakses pada tanggal 14 Feb 2021).

[17] Thermophysical Properties: Engine Oil, Unused. https://www.thermalfluidscentral.org/encyclopedia/index.php/ Thermophysical_Properties_Engine_Oil,_Unused. Thermal Fluid Central; 2011 (Diakses pada tanggal 14 Feb 2021). 